\title{
Marangoni flows induced by atmospheric-pressure plasma jets
}

Citation for published version (APA):

Berendsen, C. W. J., Veldhuizen, van, E. M., Kroesen, G. M. W., \& Darhuber, A. A. (2015). Marangoni flows induced by atmospheric-pressure plasma jets. Journal of Physics D: Applied Physics, 48(2), 025203-1/11. https://doi.org/10.1088/0022-3727/48/2/025203

DOI:

10.1088/0022-3727/48/2/025203

Document status and date:

Published: 01/01/2015

\section{Document Version:}

Publisher's PDF, also known as Version of Record (includes final page, issue and volume numbers)

\section{Please check the document version of this publication:}

- A submitted manuscript is the version of the article upon submission and before peer-review. There can be important differences between the submitted version and the official published version of record. People interested in the research are advised to contact the author for the final version of the publication, or visit the $\mathrm{DOI}$ to the publisher's website.

- The final author version and the galley proof are versions of the publication after peer review.

- The final published version features the final layout of the paper including the volume, issue and page numbers.

Link to publication

\section{General rights}

Copyright and moral rights for the publications made accessible in the public portal are retained by the authors and/or other copyright owners and it is a condition of accessing publications that users recognise and abide by the legal requirements associated with these rights.

- Users may download and print one copy of any publication from the public portal for the purpose of private study or research.

- You may not further distribute the material or use it for any profit-making activity or commercial gain

- You may freely distribute the URL identifying the publication in the public portal.

If the publication is distributed under the terms of Article 25fa of the Dutch Copyright Act, indicated by the "Taverne" license above, please follow below link for the End User Agreement:

www.tue.nl/taverne

Take down policy

If you believe that this document breaches copyright please contact us at:

openaccess@tue.nl

providing details and we will investigate your claim. 


\title{
Marangoni flows induced by atmospheric-pressure plasma jets
}

\section{W J Berendsen, E M van Veldhuizen, G M W Kroesen and A A Darhuber}

Department of Applied Physics, Eindhoven University of Technology, Eindhoven, The Netherlands

E-mail: a.a.darhuber@tue.nl

Received 12 September 2014, revised 12 November 2014

Accepted for publication 18 November 2014

Published 12 December 2014

\begin{abstract}
We studied the interaction of atmospheric-pressure plasma jets of Ar or air with liquid films of an aliphatic hydrocarbon on moving solid substrates. The hydrodynamic jet-liquid interaction induces a track of lower film thickness. The chemical plasma-surface interaction oxidizes the liquid, leading to a local increase of the surface tension and a self-organized redistribution of the liquid film. We developed a numerical model that qualitatively reproduces the formation, instability and coarsening of the flow patterns observed in the experiments. Monitoring the liquid flow has potential as an in-situ, spatially and temporally resolved, diagnostic tool for the plasma-liquid surface interaction.
\end{abstract}

Keywords: atmospheric-pressure plasma jet, thin liquid films, solutocapillary flow, Marangoni flow

(Some figures may appear in colour only in the online journal)

\section{Introduction}

Atmospheric-pressure plasma jets [1, 2] have generated significant interest for their versatile applications in material processing [1-4], surface modification [5-8], medicine [9-21] and chemical reaction engineering [22-25]. Fricke et al studied the etching of polymers using atmosphericpressure Ar plasma jets with different oxygen admixtures and found etchrates in the order of $20 \mathrm{~nm} \mathrm{~s}^{-1}$ for polyethylene [4]. Using similar plasma jets, Vogelsang et al locally reduced the water contact angle of polymer surfaces from above $90^{\circ}$ to about $30^{\circ}$ [6], mediated by surface functional groups containing oxygen and nitrogen. Dorai and Kushner presented a model for the plasma modification of polypropylene using atmospheric pressure discharges [26].

The interaction of plasmas with liquids has been studied in a variety of contexts [25, 27-29]. Mechanisms that can induce flow or surface deformations are stagnation pressure and shear of the gas flow, local temperature increase [30], chemical reactions or electric fields [31-34]. In this manuscript, we report on the interaction of cold, atmosphericpressure Ar- and air plasma jets with liquid hydrocarbon films on moving substrates. Due to the jet impact, a film thickness depression forms underneath the plasma jet. Due to the plasma-liquid interaction, the chemical composition of the liquid is altered, most likely via partial oxidation or the addition of nitrogen-containing functional groups. The liquid surface tension changes with composition and becomes spatially non-uniform, which induces solutocapillary Marangoni flows [35-41] and redistributes the liquid film. We developed a model that qualitatively reproduces many of the morphological and dynamical features observed in the experiments.

\section{Experimental methods}

\subsection{Thin liquid film deposition}

We deposited a liquid film of the essentially non-volatile liquid squalane (purity 99\%, Aldrich, product number 234311) onto polymeric substrates using spin-coating (Brewer Scientific, model CEE200). The initial film thickness was kept constant at $h_{0}=4.5 \mu \mathrm{m}$. The substrates consisted of optical-quality polycarbonate plates (Bayer, Makrofol DE1-1) of thickness $d_{\text {sub }}=750 \mu \mathrm{m}$ and dimensions of $6 \times 6 \mathrm{~cm}^{2}$. Before spincoating, we removed static surface charges [42] from the substrate using an antistatic bar (Simco-Ion MEB).

\subsection{Material properties of squalane}

The viscosity of squalane at $23^{\circ} \mathrm{C}$ is $\mu_{\text {liq }}=31.9 \mathrm{mPa} \mathrm{s}$, the surface tension [43] $\gamma=28.15 \mathrm{mN} \mathrm{m}^{-1}$, the density [44] $\rho=805 \mathrm{~kg} \mathrm{~m}^{-3}$ and the refractive index is 


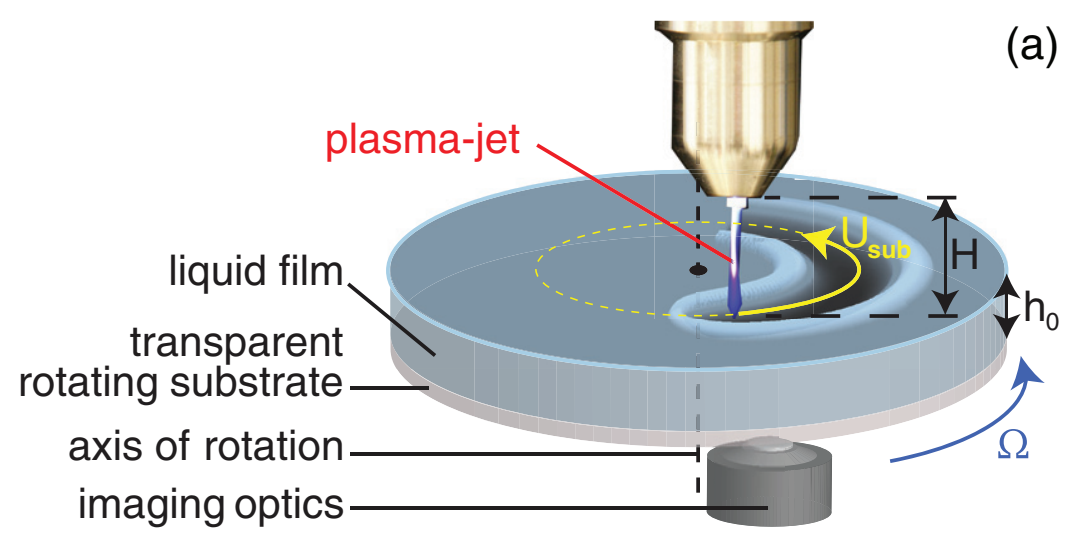

(a)
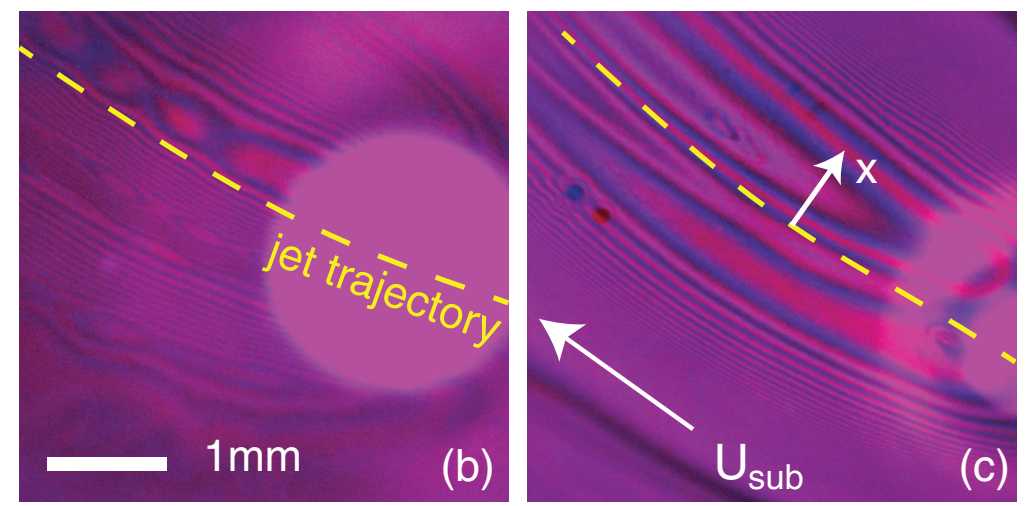

Figure 1. (a) Sketch of experimental setup for exposure of liquid films to atmospheric plasma jets. ( $b, c)$ In-situ dual-wavelength interference micrographs of liquid films exposed to $(b) \operatorname{Ar}$ and $(c)$ air plasma-jets on a substrate moving with a speed of $U_{\text {sub }}=6 \mathrm{~mm} \mathrm{~s}^{-1}$.

$n_{D}=1.452$. The self-diffusion coefficient of squalane [45] is $D_{s} \approx 3 \cdot 10^{-11} \mathrm{~m}^{2} \mathrm{~s}^{-1}$. Kowert and Watson studied the diffusion of organic solutes in squalane [46].

\subsection{Atmospheric-pressure plasma treatment}

We used a commercial atmospheric-pressure plasma jet (KinPen 09, NeoPlas Tools) [47], operated at a flowrate of approximately $11 \mathrm{~min}^{-1}$ at normal incidence onto the substrate, see figure 1 . In this fashion, the deformation of the liquid film can be visualized in-situ in transmission through the optically transparent substrate during the plasma jet impingement from the top side (figures $1(b)$ and $(c)$ ). The plasma was generated via capacitive radiofrequency (rf) excitation at $1.1 \mathrm{MHz}$ and a voltage amplitude of $2-6 \mathrm{kV}$. We used either Ar gas or purified air. We adjusted the electrical power input such that the visible length of the plasma jets was maintained at about $3 \mathrm{~mm}$. The exit nozzle diameter is $D \approx 1 \mathrm{~mm}$ resulting in a jet-Reynolds number $\operatorname{Re}_{D} \equiv \rho U$ $D / \mu \approx 1360$, which is in the laminar regime. The stand-off distance between the nozzle-exit and the liquid film was kept constant at $H=(2.5 \pm 0.1) \mathrm{mm}$. The samples were maintained in a horizontal orientation and the plasma jets were impinging from the top, perpendicular to the substrate surface. The substrates were rotated at a constant angular

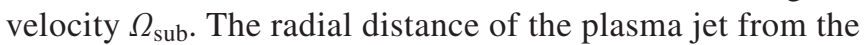
(vertical) axis of rotation was approximately $1 \mathrm{~cm}$, which implies that a value of $\Omega_{\text {sub }}=1 \mathrm{rpm}$ corresponds to a translation speed of $U_{\text {sub }} \approx 1 \mathrm{~mm} \mathrm{~s}^{-1}$. The dashed yellow lines in figure 1 indicate the jet trajectory. The diffuse regions in the right hand sides of figures $1(b)$ and $(c)$ correspond to camera pixels that were saturated by the light emission from the plasma jets.

Figure 2 shows photographs of the plasma jets and corresponding emission spectra acquired using a portable spectrometer (Ocean Optics, model USB4000). Figure 2(c) shows, besides Ar-lines, a part of the $\mathrm{N}_{2}$ second positive system (SPS) [48-50] (350-410 nm) and the $777 \mathrm{~nm}$ line of the O-atom. This is an indication of air entrainment into the plasma. Figure $2(d)$ shows the $\mathrm{N}_{2}$-SPS and $\mathrm{N}_{2}$ first negative system (FNS) [51, 52] in the wavelength range 500-900 $\mathrm{nm}$ and two O-lines at 777 and $845 \mathrm{~nm}$. The band structure between 420 and $500 \mathrm{~nm}$ is unidentified. Comparison shows that it is not $\mathrm{CH}, \mathrm{CO}, \mathrm{CN}$ or $C_{2}$. The rather large distance between the peaks indicates a heavier molecule, possibly an oxidation product of squalane.

We determined whether an electrical surface charge was induced by the interaction of the plasma with the thin liquid film, which could cause flow of electrically insulating liquids via dielectrophoresis [42]. For this purpose, we scanned the plasma-treated sample using an electrostatic voltmeter (Monroe Electronics, Isoprobe 244) with a high-resolution probe (Isoprobe 1017AEH) [42]. The probe-sample distance was approximately $0.5 \mathrm{~mm}$. There was no signature of any charge deposition along the trajectory of the plasma jet along 


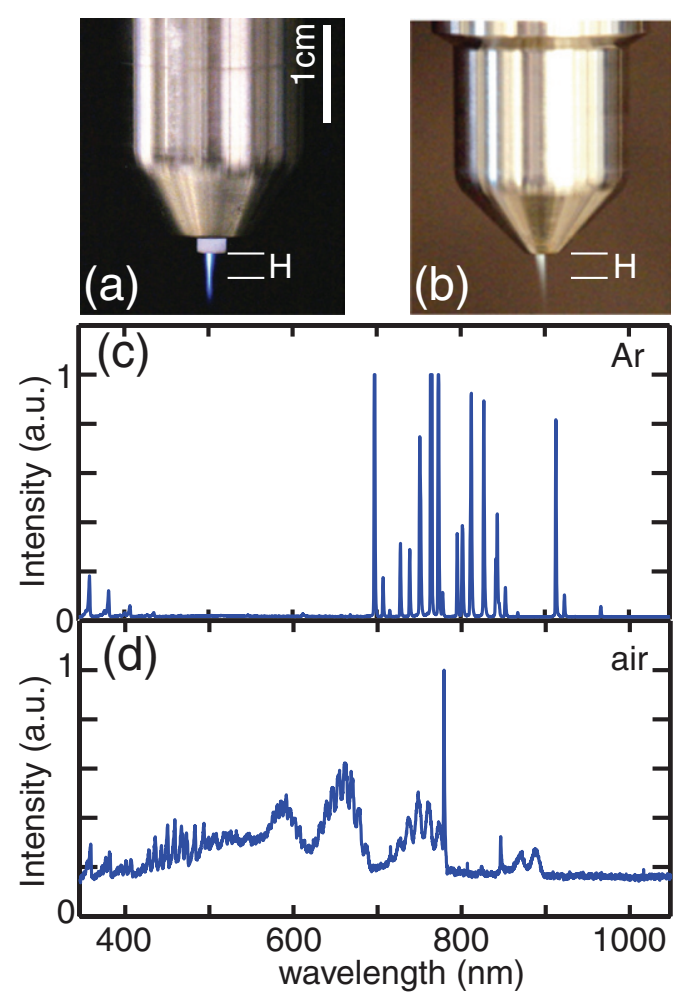

Figure 2. $(a, b)$ Photographs of the atmospheric pressure plasmajets: $(a) \mathrm{Ar}$ and $(b)$ air plasma jet. $(c, d)$ Emission spectra of $(c) \mathrm{Ar}$ and $(d)$ air plasma jets.

the substrate. The measured rms background charge density was below $1.5 \mu \mathrm{C} \mathrm{m}^{-2}$.

\subsection{Flow visualization}

After subjecting the slowly rotating liquid film to the plasma jet, we placed the sample under an upright optical microscope (Olympus BX-51), fitted with a CCD camera (AVT Pike) and a $1.25 \times$ objective. For illumination, we used an LED light source (Thorlabs, model M660L3-C1) with a center wavelength of $660 \mathrm{~nm}$. The first frame is recorded approximately one minute after termination of the plasma treatment. The evolution of the liquid height profile $h(x, y, t \gtrsim 1 \mathrm{~min})$ along the jet trajectories is visualized using optical interferometry.

\section{Experimental results}

For both Ar and air plasma jets we systematically varied the substrate rotation speed $\Omega_{\text {sub }}$. The corresponding morphology of the thin liquid films at certain times after termination of the plasma jet treatment is presented in figures 3 and 4 . The stagnation pressure and wall shear stress of the gas flow induce a depression in the liquid film along the jet trajectory [53]. Depending on the rotation rate, the remaining film thickness along the track centerline is in the range of approximately $0.1-1 \mu \mathrm{m}$. The grayscale fringes in figures 3 and 4 represent curves of constant film thickness. The dashed yellow line in figure 3(a) corresponds to the centerline of the jet trajectory as indicated in the same fashion in figure 1.
The most striking feature as a consequence of Ar plasma jet treatment is the formation of a pair of rims extending parallel to the centerline of the jet trajectory with initial separation $d_{\text {rim }} \approx 2 \mathrm{~mm}$, as indicated by the red arrows in figure $3(b)$. The rims move towards each other and merge within 5-9 min for figures $3(b)$ and $(e)$. Moreover, the rims tend to become unstable and break up into a series of droplets that grow and coarsen in time, as visualized e.g. in figures $3(b)$ and $(c)$. For air plasma jets, we observed pairs of rims for $\Omega_{\text {sub }}=0.5$ and $1 \mathrm{rpm}$ in figures $4(a)$ and $(b)$, but only a single rim for $\Omega_{\text {sub }} \geq 2 \mathrm{rpm}$.

\section{Modeling}

\subsection{A simplified model for the plasma-liquid interaction}

We hypothesize that the primary interaction between the plasma jet and the hydrocarbon is partial oxidation at the liquid-air interface as a consequence of exposure to UV/VUV radiation [54] and activated oxygen species such as $\mathrm{O}_{3}$ and O-radicals [30, 55-61]. The surface tension of e.g. alkanols and alkanoic acids is typically higher than that of the corresponding alkanes [62-64], due to the higher polarity of oxygenated molecular groups. Consequently, oxygenated liquid species tend to increase the surface tension when present as a mixture with an alkane. Thereby the surface tension of the liquid increases. Moreover, the oxygenated species desorb from the liquid-air interface, where they are formed, thus continually exposing fresh alkane molecules to the plasma environment [22].

The distribution of plasma-activated species at the liquidair interface depends on the feed gas. We assume that the lifetime of the reactive species in the gasphase outside the plasma jet is short, such that a reaction only occurs close to the direct impingement zone. In the case of Ar, activated oxygen species are produced only in the boundary layer of the jet, where oxygen is entrained from the ambient atmosphere. Therefore, reactive species can only reach the liquid film in a circular ring at the periphery of the jet as sketched in figure 5(a). In an air plasma jet, chemical reactions can occur across the entire jet impingement zone (figure 5(b)).

It is likely that a large number of different chemical species with a distribution of molecular weights (MWs) result from the plasma interaction. In the following, however, we account for the oxidized species by means of a single concentration variable $c$ and assume that surface tension has a linear dependence

$$
\gamma(c)=\gamma_{0}+\frac{\partial \gamma}{\partial c} c
$$

with a constant coefficient $\partial \gamma / \partial c>0$. For binary mixtures of alkanes and alkanols this is a realistic assumption [63].

The oxidation reaction is a highly complex process that may involve many individual steps and transitory species [26], many of which may not have been identified, yet. Therefore, the starting point for our model of the liquid redistribution is the assumption that the reaction occurs at the liquid-air interface and leads to an increase in $c_{s} \equiv c(z=h)$ at a certain rate, 


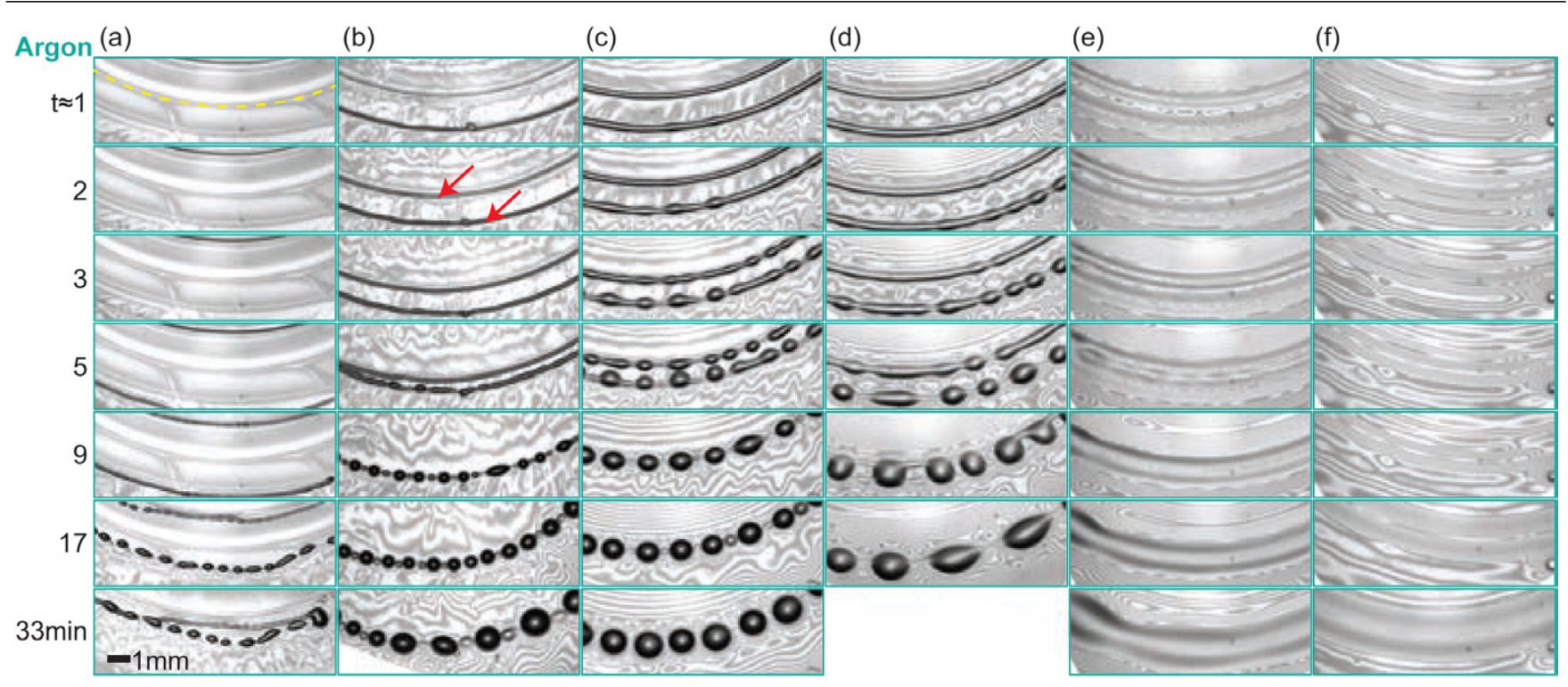

Figure 3. Optical interference micrographs of a squalane film at different times $t$ after termination of the argon plasma jet treatment at rotation speeds of (a) $\Omega_{\mathrm{sub}}=0.5 \mathrm{rpm},(b) 1 \mathrm{rpm},(c) 2 \mathrm{rpm},(d) 3 \mathrm{rpm},(e) 6 \mathrm{rpm},(f) 10 \mathrm{rpm}$.

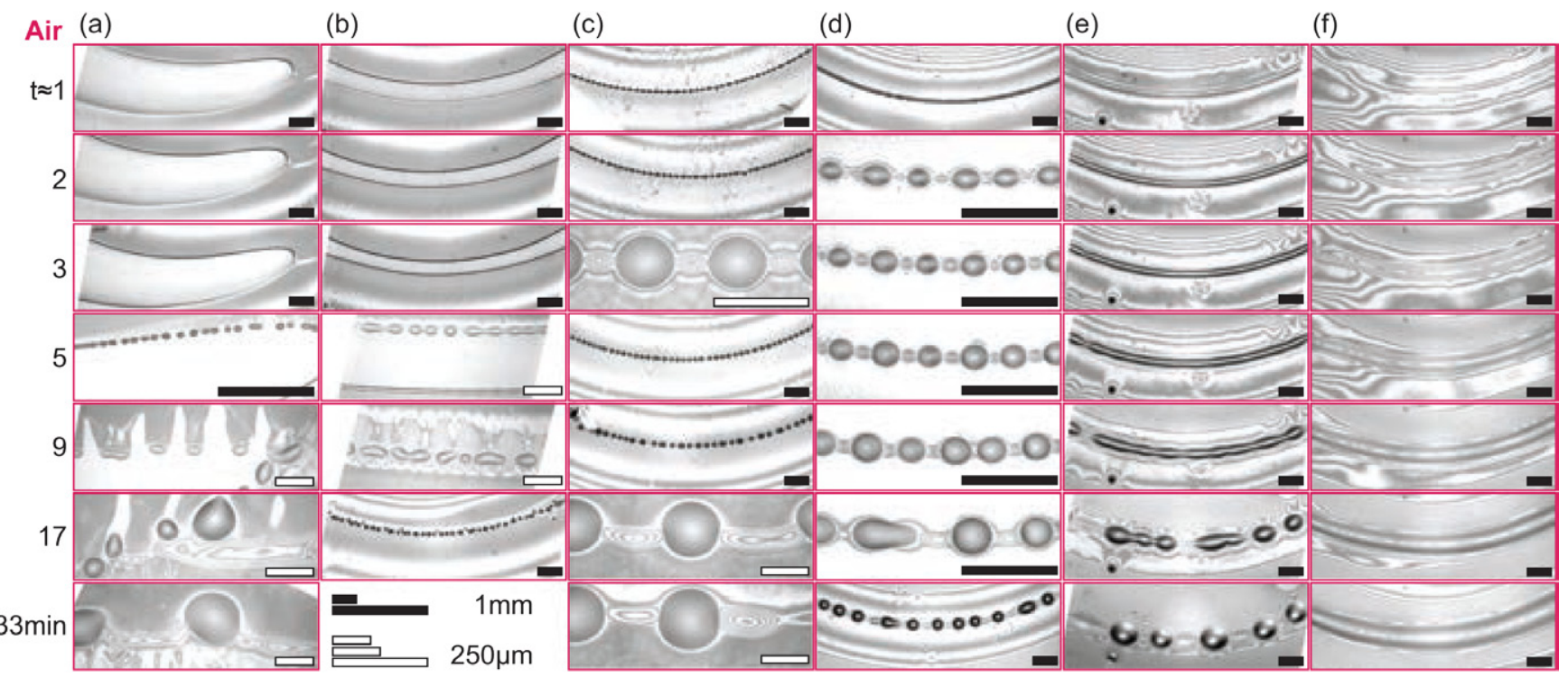

Figure 4. Optical interference micrographs of a squalane film at different times $t$ after termination of the air plasma jet treatment at rotation rates of $(a) \Omega_{\text {sub }}=0.5 \mathrm{rpm},(b) 1 \mathrm{rpm},(c) 2 \mathrm{rpm},(d) 3 \mathrm{rpm},(e) 6 \mathrm{rpm},(f) 10 \mathrm{rpm}$.

which depends on the local concentration of the activated species, the local jet velocity and boundary layer thickness.

The interaction time $t_{\text {int }}$ of the plasma with a point along the jet trajectory is given by the ratio of $D$ and the substrate speed $U_{\text {sub. }}$. A faster $U_{\text {sub }}$ will reduce $t_{\text {int }}$ and thus reduce the average concentration, while preserving the shape of the distribution. However, a small value of $U_{\text {sub }}$ gives rise to an additional dispersion effect induced by the jet shear stress $\tau_{\text {gas. }}$. A typical value [65] at the liquid-air interface is $\tau_{\text {gas }}=50 \mathrm{~Pa}$, which gives rise to a shear flow of the liquid with speed $h \tau_{\text {gas }} / \mu_{\text {liq }}$, which equals $1.5 \mathrm{~mm} \mathrm{~s}^{-1}$ for $h=1 \mu \mathrm{m}$. For a sufficiently long $t_{\text {int }}$, the widening of the distribution due to this gas induced shear flow becomes comparable to $D$, which is consistent with the increased value of $d_{\text {rim }}(t=60 \mathrm{~s}) \approx 4 \mathrm{~mm}$ observed in figure 3(a).

The oxygenated species desorbs from the surface and equilibrates with the bulk liquid across the film thickness within a time on order of $h^{2} / \mathcal{D}_{s} \approx 30-675 \mathrm{~ms}$ for $h$ in the range of $1-4.5 \mu \mathrm{m}$. We neglect material loss due to volatilization of the liquid, e.g. via the formation of $\mathrm{CO}, \mathrm{CO}_{2}, \mathrm{H}_{2} \mathrm{O}$ and other low $\mathrm{MW}$ species.

The experimental data depicted in figures 3 and 4 correspond to times $t \geq 60 \mathrm{~s}$, which by far exceed $h_{0}^{2} / \mathcal{D}_{s} \lesssim 0.7 \mathrm{~s}$. Consequently, the concentration distribution can be assumed to be vertically equilibrated. Thus, we only need to consider the height-averaged concentration defined as

$$
C \equiv \frac{1}{h} \int_{0}^{h} c \mathrm{~d} z
$$

which only depends on the lateral coordinates $x$ and $y$. We consider a Cartesian model for the flow of the liquid and the convection and diffusion of the oxidized species, where the track extends along the $y$-axis. This is permissible as the track 


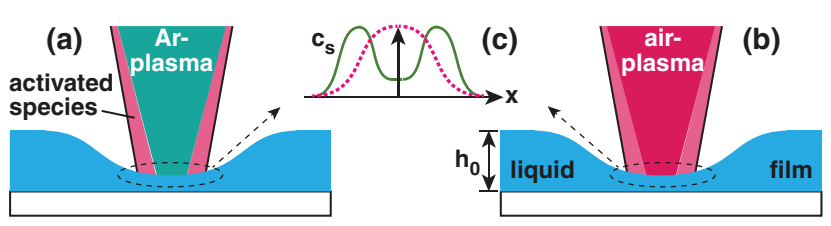

Figure 5. $(a, b)$ Sketches of the distributions of plasma-activated species. (c) Hypothetical initial species concentrations for Ar(green solid line) and air plasma jets (red dashed line).

width is much smaller than the track radius. As an initial condition we assume empirical concentration distributions of the oxidized species $C(x, t=0)$ as sketched in figure 5(c). Here, $x$ is the coordinate perpendicular to the jet trajectory and $x=0$ corresponds to its centerline (see figure 1).

We have detailed the interaction of gas jets and heat sources with liquid films in the absence of plasma previously [53, 65-67]. Therefore, we do not focus on the hydrodynamic or thermal interaction between the jet and the liquid here, but rather on the dynamics and morphology of the plasmainduced redistribution of the liquid after the jet has passed. For this reason, we consider an initial film thickness profile in the form of a parabolic depression

$$
h(x, y, t=0)=\min \left\{h_{0}, h_{c}\left(1+x^{2} / w^{2}\right)\right\} .
$$

The film thickness $h_{c}$ remaining at the track centerline after the jet has passed depends on the rotation rate [53] and is in the range of $0.1-1 \mu \mathrm{m}$. The initial concentration distributions are assumed of the form $C(x, y, t=0)=$

$$
C_{c} \Theta\left(1-x / d_{\mathrm{p}}\right)+C_{\max } \exp \left[-\left(x-d_{\mathrm{p}}\right)^{2} / w_{\mathrm{p}}^{2}\right]
$$

for Ar plasma jets and a smoothed step-function

$$
C(x, y, t=0)=C_{\max } \Theta\left(1-x / d_{\mathrm{p}}\right)
$$

for air plasma jets and are sketched in figure 5(c). The smoothed step function in equations (4) and (5) is implemented via the Comsol function fl $2 \mathrm{chs}$ as

$$
\Theta(x)=\operatorname{fl} 2 \operatorname{chs}\left(1-x / d_{\mathrm{p}}, w_{\mathrm{p}}\right),
$$

where the parameter $w_{\mathrm{p}}$ quantifies the distance over which the step function changes smoothly from 0 to 1 .

\subsection{Model for thin film redistribution}

The flow of thin liquid films is governed by the so-called lubrication equation [68]

$$
\frac{\partial h}{\partial t}+\frac{\partial Q_{x}}{\partial x}+\frac{\partial Q_{y}}{\partial y}=0
$$

where

$$
Q_{x} \equiv \frac{h^{2} \tau_{x}}{2 \mu_{\mathrm{liq}}}-\frac{h^{3}}{3 \mu_{\mathrm{liq}}} \frac{\partial p}{\partial x} \quad \text { and } \quad Q_{y} \equiv \frac{h^{2} \tau_{y}}{2 \mu_{\mathrm{liq}}}-\frac{h^{3}}{3 \mu_{\mathrm{liq}}} \frac{\partial p}{\partial y}
$$

are the volumetric flowrates,

$$
\tau_{x} \equiv \frac{\partial \gamma}{\partial x}=\frac{\partial \gamma}{\partial C} \frac{\partial C}{\partial x} \quad \text { and } \quad \tau_{y} \equiv \frac{\partial \gamma}{\partial y}=\frac{\partial \gamma}{\partial C} \frac{\partial C}{\partial y}
$$

are the Marangoni stresses [36] along the $x$ - and $y$-directions and

$$
p=-\gamma\left(\frac{\partial^{2} h}{\partial x^{2}}+\frac{\partial^{2} h}{\partial y^{2}}\right)+\rho g h
$$

is the augmented pressure, representing capillary and hydrostatic pressure contributions. Here, $g=9.81 \mathrm{~m} \mathrm{~s}^{-2}$ is the gravitational acceleration. The terms containing $\tau_{x}$ and $\tau_{y}$ represent Marangoni fluxes in response to surface tension gradients, which are caused by gradients in concentration of the oxidized species $C$ owing to equation (1). Generally, the direction of Marangoni flow in thin liquid films is from regions of lower towards regions of higher surface tension. The non-uniform species distribution that sets up the surface tension gradients, however, changes continuously due to diffusion and convection with the flow. Therefore, equation (7) is coupled to a convection-diffusion equation [69] that governs the dynamics of $C(x, y, t)$

$$
\begin{aligned}
h \frac{\partial C}{\partial t} & +Q_{x} \frac{\partial C}{\partial x}+Q_{y} \frac{\partial C}{\partial y} \\
& =\frac{\partial}{\partial x}\left(h \mathcal{D}_{s} \frac{\partial C}{\partial x}\right)+\frac{\partial}{\partial y}\left(h \mathcal{D}_{s} \frac{\partial C}{\partial y}\right) .
\end{aligned}
$$

We solved the set of equations (7)-(11) numerically using the finite element software Comsol 3.5a. The computational domain extends typically a distance $L_{x}=10 \mathrm{~mm}$ normal to the jet centerline and - in the case of 2D simulations - a distance of $L_{y}=2-8 \mathrm{~mm}$ along the jet centerline. The boundary conditions were chosen as

$$
\frac{\partial h}{\partial x}=0, \quad \frac{\partial p}{\partial x}=0 \quad \text { and } \quad \frac{\partial C}{\partial x}=0 .
$$

at $x=0$ and $x=L_{x}$ and

$$
\frac{\partial h}{\partial y}=0, \quad \frac{\partial p}{\partial y}=0 \quad \text { and } \quad \frac{\partial C}{\partial y}=0
$$

at $y=0$ and $y=L_{y}$, all of which represent mirror symmetries. The boundary at $x=L_{x}$ is sufficiently remote from the centerline, such that the surface deformation does not reach it within the typical duration of an experiment.

\subsection{One-dimensional model calculations}

We first performed one-dimensional model calculations. Figure 6(a) shows a typical time evolution of the film thickness $h(x, t)$ and the concentration profile $C(x, t) / C_{\max }$ after interaction with an Ar plasma jet. The individual curves are offset along the ordinate for clarity.

The general morphology observed in figure 3 is well reproduced. Two rims form within seconds, move towards each other and coalesce after about $1000 \mathrm{~s}$. The rim profiles do not transition smoothly into their surrounding, but rather strong thinning with a minimum film thickness on order of $20 \mathrm{~nm}$ occurs at the rim edges (indicated by the red and blue triangles in figure 6(a). The concentration profile exhibits selfsteepening as indicated in figure $6(b)$ and has the appearance of a shock-wave. The origin is the strong film thinning at the 

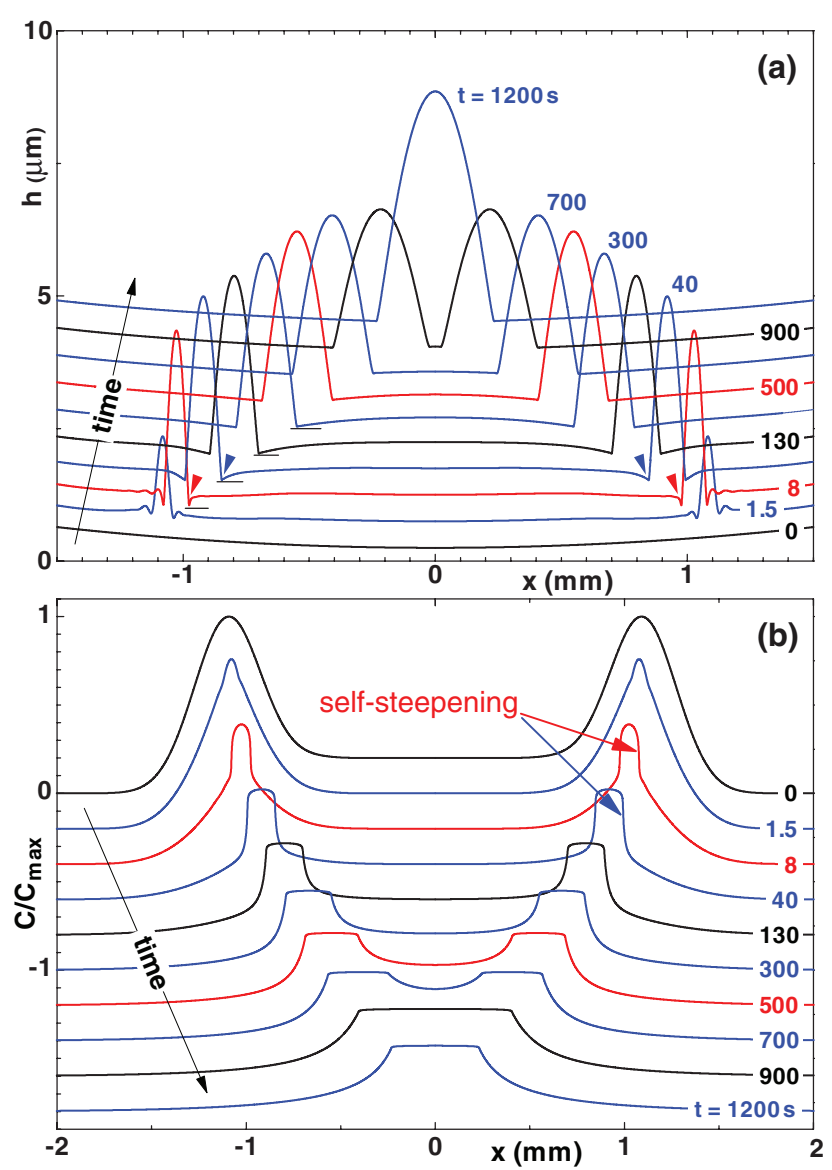

Figure 6. Time evolution of $(a)$ the height profile $h(x, t)$ and $(b)$ the concentration profile $C(x, t) / C_{\max }$ for an Ar plasma jet treatment and parameters $C_{c} / C_{\max }=0.2, \mathcal{D}_{s}=3 \cdot 10^{-10} \mathrm{~m}^{2} \mathrm{~s}^{-1}, h_{c}=250 \mathrm{~nm}$, $w=1.2 \mathrm{~mm}, d_{\mathrm{p}}=1.1 \mathrm{~mm}, w_{\mathrm{p}}=250 \mu \mathrm{m}, C_{c} / C_{\max }=0.2$ and $\Delta \gamma=2 \mathrm{mN} \mathrm{m}^{-1}$. The individual curves are progressively shifted along the ordinate for clarity by increments of $(a) 0.5 \mu \mathrm{m}$ and $(b)-0.2$.

rim edges, which constitutes a high resistance to mass transfer and causes the very steep concentration gradients. Inside the ridge, Marangoni convection efficiently equilibrates the concentration distribution, giving rise to the flat-top-like profile. The concentration distribution thus induces both inwards- and outwards-oriented Marangoni stresses. However, due to the larger overall concentration difference at the exterior rim edge, the inwards-oriented forces prevail and eventually induce coalescence.

Figure 7 shows a typical evolution of the height- and concentration profiles for the case of an air plasma jet. The most striking difference is that the coalescence time is more than a factor of 10 shorter. Moreover, the maximum concentration remains at a value of approximately one until coalescence and the self-steepening observed with Ar plasma jets is much less pronounced. Consistent with the shallower concentration gradients, also the film thinning is less pronounced and is observed only at the exterior edges of the rims, but not at the interior edges. The substantially faster coalescence for air is thus due to the absence of film thinning inbetween the two rims as well as the absence of outwards-oriented solutocapillary driving forces as compared to the Ar case.
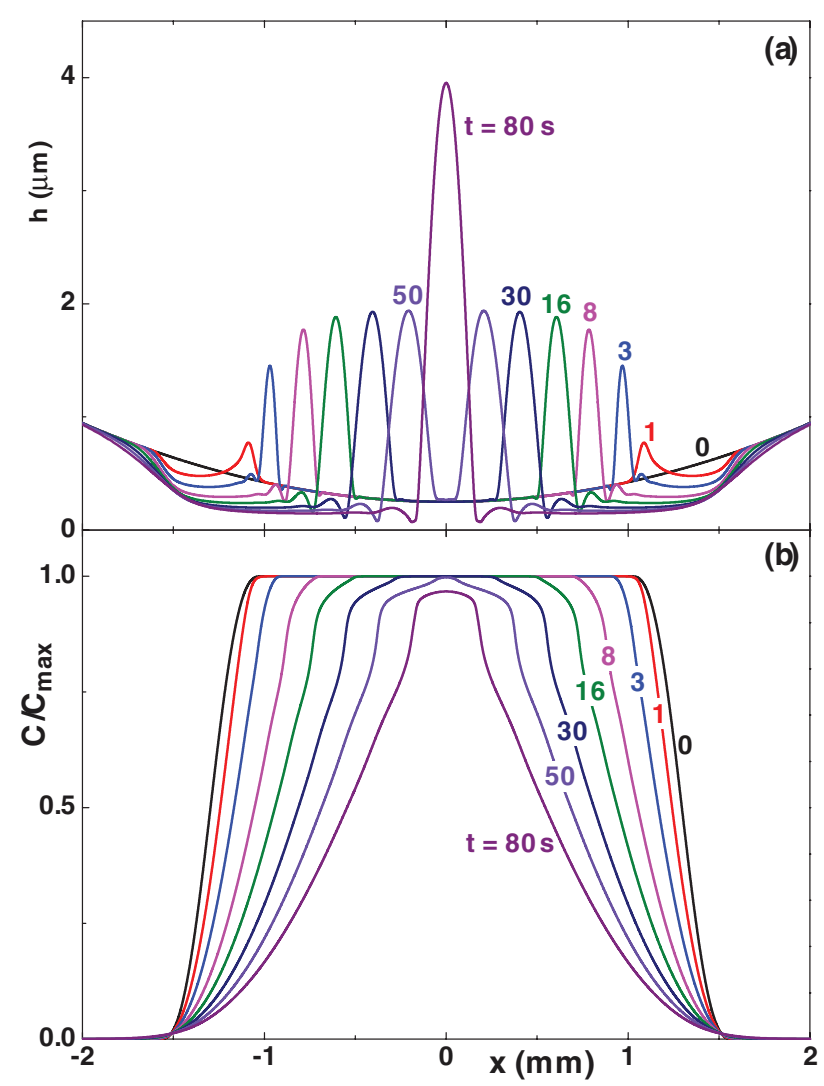

Figure 7. Time evolution of $(a)$ the height profile $h(x, t)$ and $(b)$ the concentration profile $C(x, t) / C_{\max }$ for an air plasma jet treatment and parameters $D_{s}=3 \cdot 10^{-10} \mathrm{~m}^{2} \mathrm{~s}^{-1}, h_{c}=250 \mathrm{~nm}, w=1.2 \mathrm{~mm}$, $d_{\mathrm{p}}=1.1 \mathrm{~mm}, w_{\mathrm{p}}=250 \mu \mathrm{m}, C_{c} / C_{\max }=0.2$ and $\Delta \gamma=2 \mathrm{mN} \mathrm{m}^{-1}$.

Figure $8(a)$ presents numerical simulations of the rim coalescence time $t_{c}$ as a function of the total surface tension modulation amplitude $\Delta \gamma \equiv \frac{\partial \gamma}{\partial c} C_{\max }$. For $\Delta \gamma$ increasing, $t_{c}$ decreases, because the convection rate is proportional to the surface tension gradient $\partial \gamma / \partial x$. For an air plasma jet $\left(C_{c} / C_{\max }=1\right), t_{c}$ is more than a factor of 10 shorter than for Ar. Specifically for $\Delta \gamma \gtrsim 2.5 \mathrm{mN} \mathrm{m}^{-1}, t_{c}$ is shorter than $1 \mathrm{~min}$ as indicated by the blue rectangle, which is consistent with the observation of a single rim in figures $4(c)-(e)$. For an air plasma jet $\left(C_{c} / C_{\max }=1\right), t_{c}$ to good approximation scales as $t_{c} \sim(\Delta \gamma)^{-1}$, because the maximum concentration, occurring at $x=0$, remains at the initial level (see figure $7(b)$ ). Due to the self-steepening effect observed with Ar plasma jets and the dilution-induced decrease of the maximum concentration level (figure $5(e)$ ), the dependence of $t_{c}$ on $\Delta \gamma$ is weaker: to good approximation $t_{c} \sim(\Delta \gamma)^{-0.6}$ for $C_{c}=0.2$.

Figure $8(b)$ illustrates the influence of the species diffusion coefficient $\mathcal{D}_{s}$ on the coalescence time $t_{c}$. For an air plasma jet $\left(C_{c} / C_{\max }=1\right), t_{c}$ is independent of $\mathcal{D}_{s}$ for $\mathcal{D}_{s} \lesssim 6 \cdot 10^{-10} \mathrm{~m}^{2} \mathrm{~s}^{-1}$. For Ar plasma jets $\left(C_{c} / C_{\max }<1\right), t_{c}$ increases with decreasing $\mathcal{D}_{s}$ for $\mathcal{D}_{s} \lesssim 1 \cdot 10^{-9} \mathrm{~m}^{2} \mathrm{~s}^{-1}$. The dashed line in figure $8(b)$ represents the diffusional equilibration time $t_{\mathrm{eq}}=(\Delta x)^{2} / \mathcal{D}_{s}$ for a distance $\Delta x \approx 2 \mathrm{~mm}$ approximately equal to the track width. When the curves in figure $8(b)$ get close to this limit, $t_{c}$ increases, because diffusion becomes so strong that it quenches the driving force of the flow. 

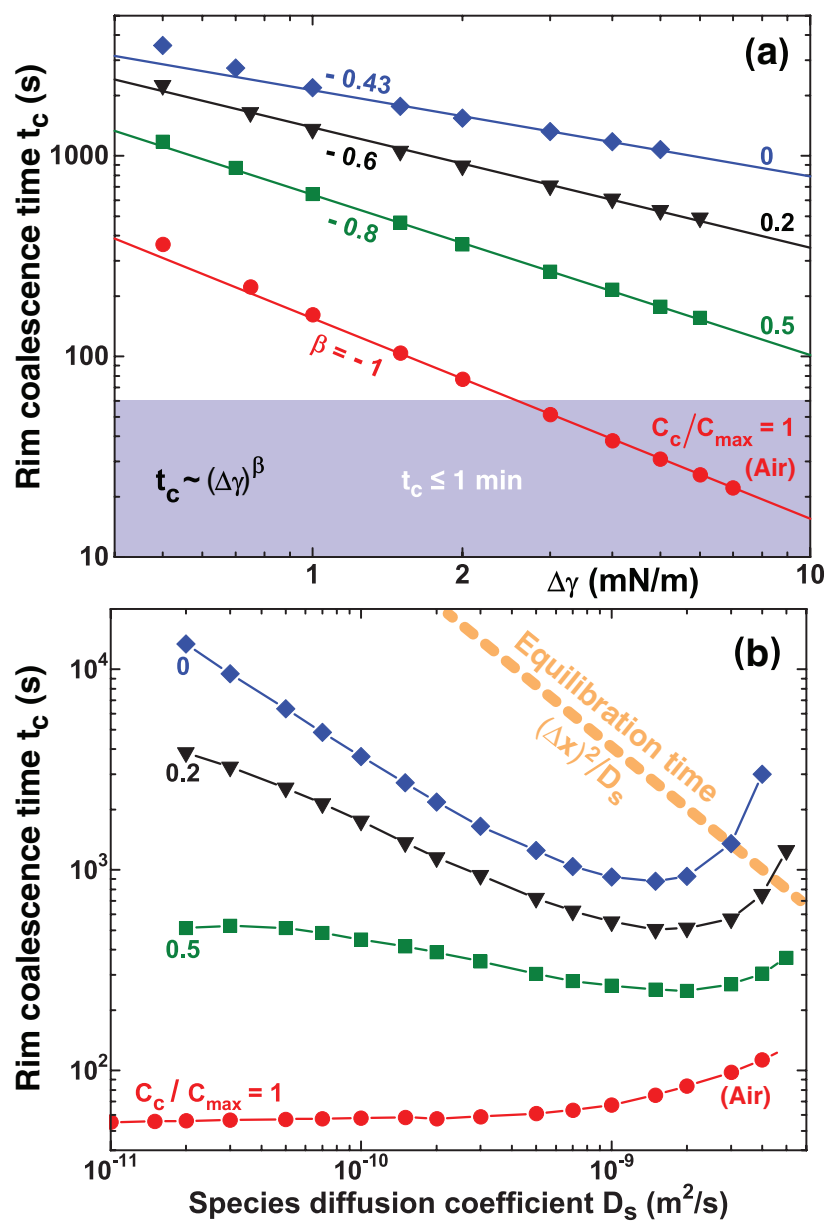

Figure 8. Rim coalescence time $t_{c}$ as a function of $(a)$ the total surface tension modulation amplitude $\Delta \gamma$ and $(b)$ the species diffusion coefficient $\mathcal{D}_{s}$. The parameters that were not varied in $(a, b)$ were set to $\mathcal{D}_{s}=3 \cdot 10^{-10} \mathrm{~m}^{2} \mathrm{~s}^{-1}, h_{c}=180 \mathrm{~nm}, w=1.2 \mathrm{~mm}$, $d_{\mathrm{p}}=1.1 \mathrm{~mm}, w_{\mathrm{p}}=330 \mu \mathrm{m}$ and $\Delta \gamma=2 \mathrm{mN} \mathrm{m}^{-1}$. The solid lines in (a) represent power law relations $t_{c} \sim \Delta \gamma^{\beta}$.

Figure 9(a) illustrates the influence of the center film thickness $h_{c}$ on $t_{c}$. A larger value of $h_{c}$ increases the coalescence time for an air plasma jet treatment $\left(C_{c} / C_{\max }=1\right)$, which is intuitively consistent with the notion that thicker films provide for a higher mobility of the rim. However, for an Ar plasma jet and $C_{c} / C_{\max } \leq 0.2$, a smaller value of $h_{c}$ slightly speeds up coalescence, which is perhaps counterintuitive, but agrees with the trend observed in figures $3(b)-(d)$.

Figure $9(b)$ illustrates the influence of the initial width of the species distribution $w_{\mathrm{p}}$ on $t_{c}$. Since according to equation (4) the total mass of species increases with increasing $w_{\mathrm{p}}$ (for $C_{c} / C_{\max }<1$ ), which foregoes the dilution-induced reduction in driving force, the coalescence time eventually decreases for large $w_{\mathrm{p}}$. For an air plasma treatment $\left(C_{c} / C_{\max }=1\right)$, the coalescence time is well approximated by a power law $t_{c} \sim w_{\mathrm{p}}^{-0.53}$ as represented by the dashed line in figure $9(b)$.

Figure 10 shows experimental and numerical results for the rim separation $d_{\text {rim }}$ as a function of time. The influence of the substrate rotation rate $\Omega_{\text {sub }}$, which determines the interaction time with the passing plasma jet, is presented in figure $10(a)$. Presumably, a smaller value of $\Omega_{\text {sub }}$ induces a larger $\Delta \gamma$, which
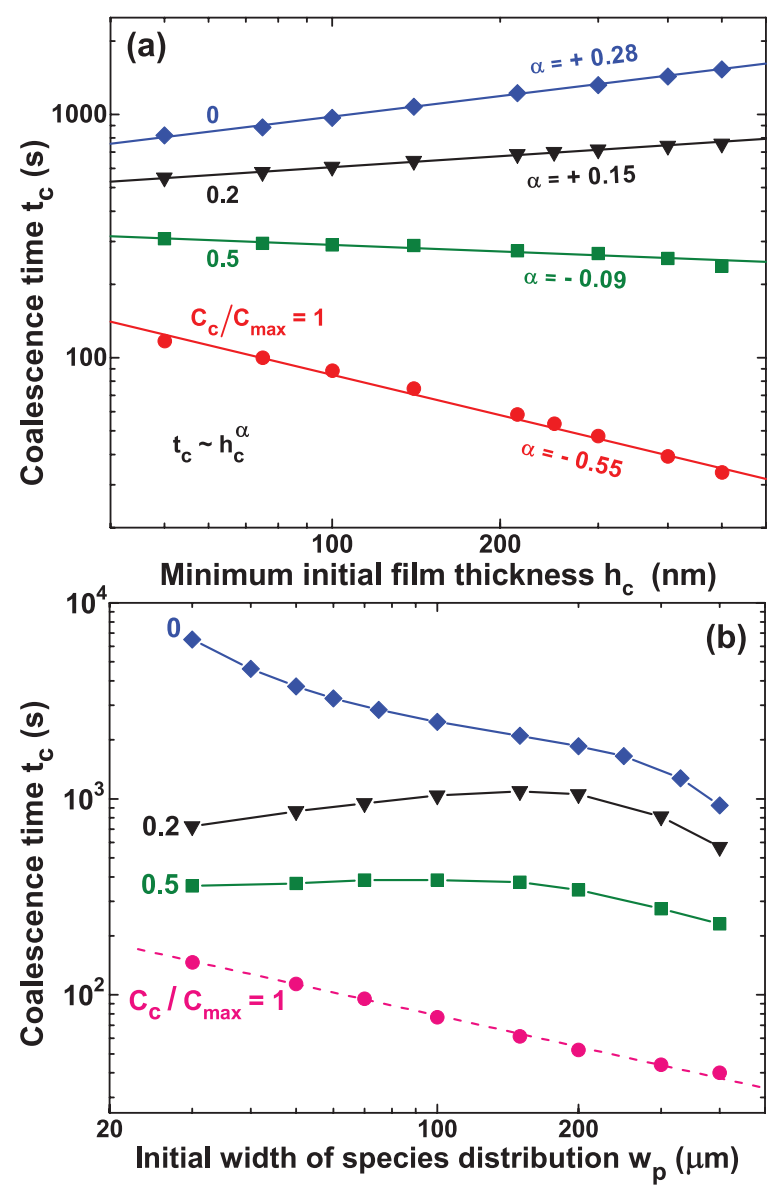

Figure 9. Rim coalescence time $t_{c}$ as a function of $(a)$ the minimum film thickness in the track $h_{c}$ and $(b)$ the initial width of the species distribution $w_{p}$. The parameters that were not varied in $(a, b)$ were set to $D_{s}=3 \cdot 10^{-10} \mathrm{~m}^{2} \mathrm{~s}^{-1}, h_{c}=180 \mathrm{~nm}, w=1.2 \mathrm{~mm}, d_{\mathrm{p}}=1.1 \mathrm{~mm}$, $w_{\mathrm{p}}=330 \mu \mathrm{m}$ and $\Delta \gamma=2 \mathrm{mN} \mathrm{m}^{-1}$. The solid lines in $(a)$ and the dashed line in $(b)$ represent power law relations $t_{c} \sim h_{c}^{\alpha}$ and $t_{c} \sim w_{\mathrm{p}}^{\beta}$, respectively.

leads to a smaller value of $t_{c}$, which is consistent with the simulation results in figures $10(b)$ and 8 . The initial species distribution, as parametrized by $C_{c} / C_{\max }$ has a strong influence on the shape of $d_{\text {rim }}(t)$ as detailed in figure $10(c)$. For $C_{c} / C_{\max }=0.5$ and 1 , the rim migration speed is monotonically decreasing from the onset essentially until coalescence. In contrast, for $C_{c} / C_{\max }=0$ and 0.2 the curves have an inflection point, i.e. the rim migration speed accelerates as $t$ approaches $t_{c}$, which is consistent with the experimental data in figure $10(a)$.

\subsection{Two-dimensional simulations}

The one-dimensional simulations presented in the previous section are computationally efficient and reproduce many features of the experiments. However, they inherently preclude any study of the rim instability and the growth- and coarsening dynamics of the droplet arrays. For this reason we also performed two-dimensional simulations, of which figure 11 presents a typical example. Pseudocolor plots of the 2D height profile $h(x, y, t)$ are shown at different times after passing of the plasma jet. The computational domain had dimensions of 

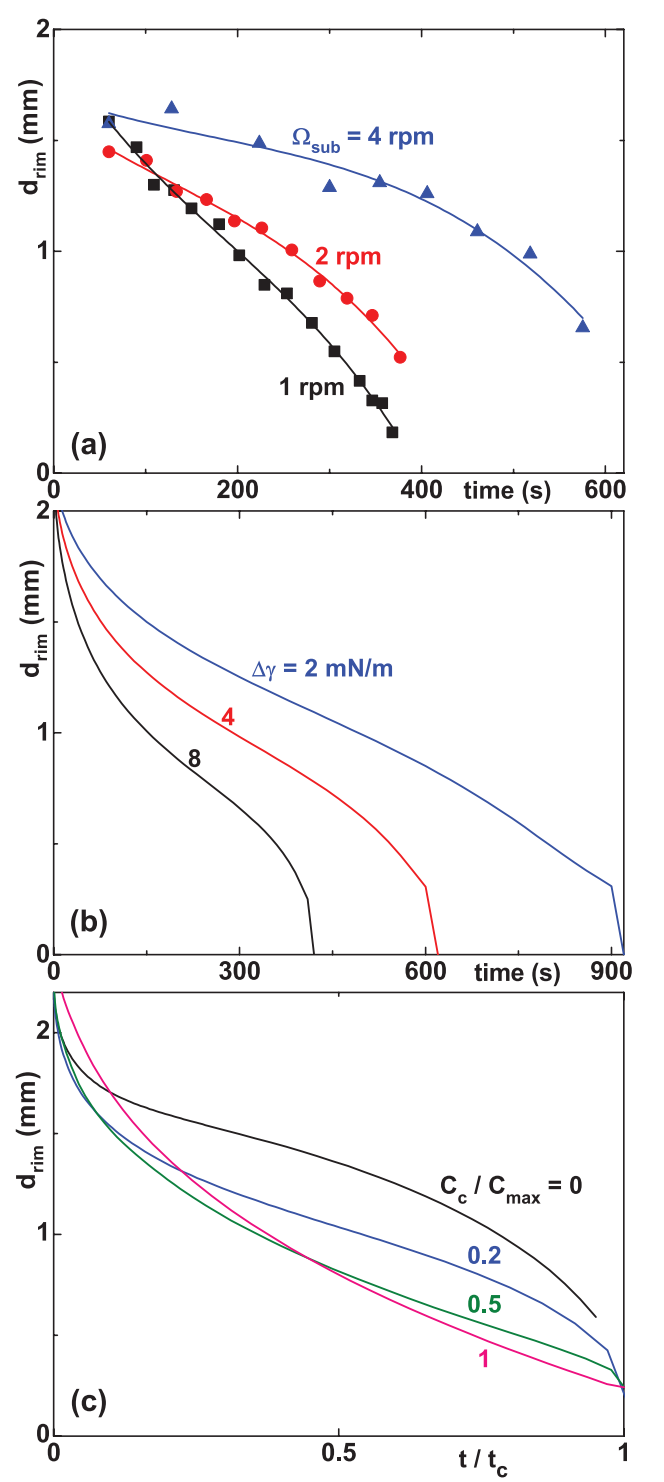

Figure 10. Rim separation $d_{\text {rim }}$ as a function of time. $(a)$ Experimental data for an Ar plasma jet and different substrate rotation rates $\Omega_{\text {sub }}=1,2$ and $4 \mathrm{rpm}$. The solid lines are guides to the eye. (b) Numerical simulations of $d_{\text {rim }}(t)$ for different surface tension modulation amplitudes $\Delta \gamma=2,4$ and $8 \mathrm{mN} \mathrm{m}^{-1}$ and parameters $C_{c} / C_{\max }=0.2, \mathcal{D}_{s}=3 \cdot 10^{-10} \mathrm{~m}^{2} \mathrm{~s}^{-1}, h_{c}=180 \mathrm{~nm}$, $w=1.2 \mathrm{~mm}, d_{\mathrm{p}}=1.1 \mathrm{~mm}, w_{\mathrm{p}}=330 \mu \mathrm{m}$. (c) Numerical simulations of $d_{\text {rim }}(t)$ for different initial species distributions $C_{c} / C_{\max }=0$, $0.2,0.5$ and 1 and parameters $\mathcal{D}_{s}=1 \cdot 10^{-10} \mathrm{~m}^{2} \mathrm{~s}^{-1}, h_{c}=250 \mathrm{~nm}$, $w=1.2 \mathrm{~mm}, d_{\mathrm{p}}=1.1 \mathrm{~mm}, w_{\mathrm{p}}=250 \mu \mathrm{m}$ and $\Delta \gamma=2 \mathrm{mN} \mathrm{m}^{-1}$.

$L_{y}=2 \mathrm{~mm}$ and typically $L_{x}=5 \mathrm{~mm}$. For clarity the results are mirrored across $x=0$ in figure $11(a-g)$ and additionally across $y=0$ in figure $11(h)$.

The formation and instability of the rims and the subsequent coarsening of the resulting droplets observed in figure 3 is qualitatively well reproduced. The instability wavelength at the onset is $\lambda_{o} \approx 0.45 \mathrm{~mm}$ in figure $11(b)$. Only very weak dependencies of $\lambda_{o}$ on $h_{c}$ and $C_{c} / C_{\max }$ were observed. Large values of $\mathcal{D}_{s}$ or small values of $\Delta \gamma$ tend to delay the onset, increase $\lambda_{o}$ or even suppress the occurrence of the instability, which is consistent with the trend observed in figures $3(d)-(f)$ and $4(d)-(f)$.

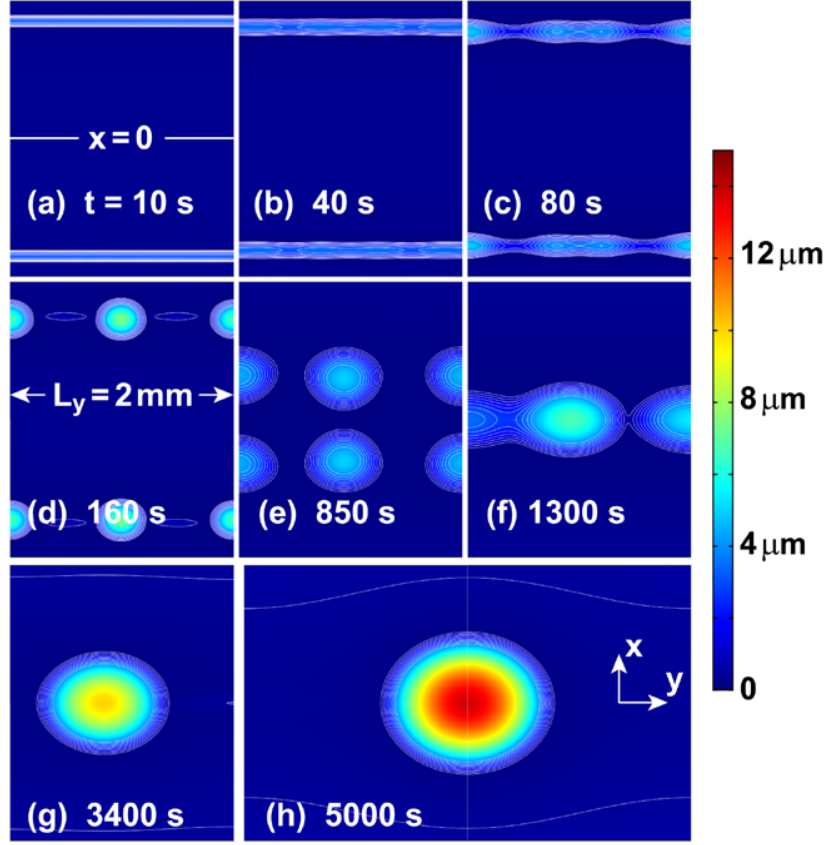

Figure 11. Pseudocolor plot of film thickness evolution $h(x, y, t)$ for $\Delta \gamma=2 \mathrm{mN} \mathrm{m}^{-1}$ and parameters $C_{c}=0, \mathcal{D}_{s}=5 \cdot 10^{-10} \mathrm{~m}^{2} \mathrm{~s}^{-1}$ and $h_{c}=250 \mathrm{~nm}$. The white line in panel $(a)$ labeled $x=0$ represents the jet trajectory. The parameter $L_{y}=2 \mathrm{~mm}$ in $(d)$ is the width of the computational domain.

The driving forces of the coalescence and coarsening of the droplets are on the one hand a reduction of interfacial area and on the other hand differences in the overall species concentration in neighboring droplets. This concentration difference corresponds to a surface tension difference that causes the droplet with lower surface tension to flow towards the droplet with higher surface tension [70-78]. Since the concentration differences in neighboring droplets are very likely small, a coalescence delay [73-78] does not occur.

\section{Discussion}

According to figure $8(b)$, a value of $\mathcal{D}_{s}$ close to the self-diffusion coefficient of squalane $3 \cdot 10^{-11} \mathrm{~m}^{2} \mathrm{~s}^{-1}$ does not give a coalescence time $t_{c}$ in the experimentally observed range of 400-600 s for Ar plasma jets. Rather, a much larger value of $\mathcal{D}_{s}$ is required for a good match with the experiments in figure 3 , which may indicate molecular fragmentation as a consequence of plasma-induced oxidation.

There is an inherent ambiguity in the model as all results are only sensitive to the product $(\partial \gamma / \partial C)(\partial C / \partial x)$, which scales as $(\partial \gamma / \partial C)\left(C_{\max } / w_{\mathrm{p}}\right)$, but not separately to $(\partial \gamma / \partial C)$ and $C_{\max }$. However, if the reaction products are known, the Marangoni coefficient $(\partial \gamma / \partial C)$ can be measured independently in principle. In this fashion, the experiments allow for an indirect, but otherwise fast and simple visualization of the species concentration distribution. Although we monitored the deformation of thin liquid films after the jet has passed, the technique also has the potential to serve as an in-situ diagnostic tool for elucidating the dynamics and spatial dependence of the interaction between cold atmospheric plasma jets and condensed matter. 


\section{Summary}

In summary, we studied the interaction of cold, atmosphericpressure plasma jets of Ar or air with liquid hydrocarbon films on moving substrates. Due to the chemical plasma-surface interaction, the liquid most likely becomes oxidized, leading to a local surface tension increase and subsequent solutocapillary redistribution. In the case of an Ar plasma jet, two rivulets are formed that move towards the center of the jet trajectory. In the case of an air plasma jet, a single rivulet is observed in the center of the track. These rims tend to be unstable and breakup into regular arrays of droplets that grow and coarsen over time. We systematically studied the influence of the substrate speed, which determines the plasma-liquid interaction time and thus the degree of oxidation. We developed a numerical model that qualitatively reproduces the experimental observations, i.e. the formation of rims, their coalescence, instability and coarsening.

\section{Acknowledgments}

This work is part of the research programme 'Contact Line Control during Wetting and Dewetting' (CLC) of the 'Stichting voor Fundamenteel Onderzoek der Materie (FOM)', which is financially supported by the 'Nederlandse Organisatie voor Wetenschappelijk Onderzoek (NWO)'. The CLC programme is co-financed by ASML and Océ. Moreover, the authors gratefully acknowledge that this research is supported partially by the Dutch Technology Foundation STW, applied science division of NWO and the Technology Program of the Ministry of Economic Affairs.

\section{References}

[1] Jeong J Y, Babayan S E, Schütze A, Tu V J, Park J, Henins I, Selwyn G S and Hicks R F 1999 Etching polyimide with a nonequilibrium atmospheric-pressure plasma jet J. Vac. Sci. Technol. A 172581

[2] Lee B-J, Kusano Y, Kato N, Naito K, Horiuchi T and Koinuma H 1997 Oxygen plasma treatment of rubber surface by the atmospheric pressure cold plasma torch Japan. J. Appl. Phys. 36 2888-91

[3] Kim S I and Lee C W 2008 Plasma liquid-vapor activation (PLVA) effect of the semiconductor etching process for photoresist residues J. Korean Phys. Soc. 531375

[4] Fricke K, Steffen H, von Woedtke T, Schröder K and Weltmann K-D 2011 High rate etching of polymers by means of an atmospheric pressure plasma jet Plasma Process. Polym. 8 51-8

[5] Strobel M, Jones V, Lyons C S, Ulsh M, Kushner M J, Dorai R and Branch M C 2003 A Comparison of corona-treated and flame-treated polypropylene films Plasmas Polym. 8 61-95

[6] Vogelsang A, Ohl A, Steffen H, Foest R, Schröder K and Weltmann K-D 2010 Locally resolved analysis of polymer surface functionalization by an atmospheric pressure argon microplasma jet with air entrainment Plasma Process. Polym. 7 16-24

[7] Barankin M D, Gonzalez E, Habib S B, Gao L, Guschl P C and Hicks R F 2009 Hydrophobic films by atmospheric plasma curing of spun-on liquid precursors Langmuir 25 2495-500

[8] Olszewski P, Willett T C, Theodosiou E, Thomas O R T and Walsh J L 2013 In situ modification of chromatography adsorbents using cold atmospheric pressure plasmas Appl. Phys. Lett. 102204104

[9] Laroussi M and Lu X 2005 Room-temperature atmospheric pressure plasma plume for biomedical applications Appl. Phys. Lett. 87113902

[10] Laroussi M 2005 Low temperature plasma-based sterilization: overview and state-of-the-art Plasma Process. Polym. 2 391-400

[11] Sato T, Miyahara T, Doi A, Ochiai S, Urayama T and Nakatani T 2006 Sterilization mechanism for Escherichia coli by plasma flow at atmospheric pressure Appl. Phys. Lett. 89073902

[12] Deng X T, Shi J J, Chen H L and Kong M G 2007 Protein destruction by atmospheric pressure glow discharges Appl. Phys. Lett. 90013903

[13] Lu X P, Jiang Z H, Xiong Q, Tang Z Y, Hu X W and Pan Y 2008 An $11 \mathrm{~cm}$ long atmospheric pressure cold plasma plume for applications of plasma medicine Appl. Phys. Lett. 92081502

[14] Nosenko T, Shimizu T and Morfill G E 2009 Designing plasmas for chronic wound disinfection New J. Phys. 11115013

[15] Kong M G, Kroesen G, Morfill G, Nosenko T, Shimizu T, van Dijk J and Zimmermann J L 2012 Plasma medicine: an introductory review New J. Phys. 11115012

[16] Clément F, Lecoq E, Duday D, Belmonte T, Audinot J$\mathrm{N}$, Lentzen E, Penny C, Cauchie H-M and Choquet P 2011 NanoSIMS50 analyses of $\mathrm{Ar} /{ }^{18} \mathrm{O}_{2}$ plasma-treated Escherichia coli bacteria New J. Phys. 13113040

[17] Gazeli K, Noel C, Clément F, Dauge C, Svarnas P and Belmonte T 2013 A study of helium atmospheric-pressure guided streamers for potential biological applications Plasma Sources Sci. Technol. 22025020

[18] Duday D, Clément F, Lecoq E, Penny C, Audinot J-H, Belmonte T, Kutasi K, Cauchie H-M and Choquet P 2013 Study of reactive oxygen or/and nitrogen species binding processes on E. Coli bacteria with mass spectrometry isotopic nanoimaging Plasma Process. Polym. 10864

[19] Zhang Q, Liang Y, Feng H, Ma R, Tian Y, Zhang J and Fang J 2014 A study of oxidative stress induced by non-thermal plasma-activated water for bacterial damage Appl. Phys. Lett. 104013701

[20] Zhang Q, Liang Y, Feng H, Ma R, Tian Y, Zhang J and Fang J 2013 A study of oxidative stress induced by non-thermal plasma-activated water for bacterial damage Appl. Phys. Lett. 102203701

[21] Kim K, Ahn H J, Lee J-H, Kim J-H, Yang S S and Lee J-S 2014 Cellular membrane collapse by atmospheric-pressure plasma jet Appl. Phys. Lett. 104013701

[22] Suhr H, Schmid H, Pfeundschuh H and Iacocca D 1984 Plasma oxidation of liquids Plasma Chem. Plasma Process. 4285

[23] Tezuka M and Iwasaki M 1999 Liquid-phase reactions induced by gaseous plasma. Decomposition of benzoic acids in aqueous solution Plasmas Ions 2 23-6

[24] Richmonds C and Sankarana R M 2008 Plasma-liquid electrochemistry: rapid synthesis of colloidal metal nanoparticles by microplasma reduction of aqueous cations Appl. Phys. Lett. 93131501

[25] Richmonds C, Witzke M, Bartling B, Lee S W, Wainright J, Liu C-C and Sankaran R M 2011 Electron-transfer reactions at the plasma-liquid interface J. Am. Chem. Soc. 13317582 
[26] Dorai R and Kushner M J 2003 A model for plasma modification of polypropylene using atmospheric pressure discharges J. Phys. D: Appl. Phys. 36666

[27] Watson P K, Chadband W G and Sadeghzadeh-Araghi M 1991 The role of electrostatic and hydrodynamic forces in the negative-point breakdown of liquid dielectrics IEEE Transact. Electr. Insul. 26543

[28] Bruggeman P and Leys C 2009 Non-thermal plasmas in and in contact with liquids J. Phys. D: Appl. Phys. 42053001

[29] Hamdan A, Kosior F, Noel C, Henrion G, Audinot J-N, Gries T and Belmonte T 2013 Plasma-surface interaction in heptane J. Appl. Phys. 113213303

[30] Shimizu T, Iwafuchi Y, Morfill G E and Sato T 2011 Formation of thermal flow fields and chemical transport in air and water by atmospheric plasma New J. Phys. 13053025

[31] Kawamoto H and Umezu S 2005 Electrohydrodynamic deformation of water surface in a metal pin to water plate corona discharge system J. Phys. D: Appl. Phys. 38 887-94

[32] Chiragwandi Z G, Nur O, Willander M and Panas I 2005 Vortex rings in pure water under static external electric field Appl. Phys. Lett. 87153109

[33] Bruggeman P, Graham L, Degroote J, Vierendeels J and Leys C 2007 Water surface deformation in strong electrical fields and its influence on electrical breakdown in a metal pinwater electrode system J. Phys. D: Appl. Phys. 40 4779-86

[34] Verreycken T, Bruggeman P and Leys C 2009 Anode pattern formation in atmospheric pressure air glow discharges with water anode J. Appl. Phys. 105083312

[35] Marangoni C 1871 Ueber die Ausbreitung der Tropfen einer Flüssigkeit auf der Oberfläche einer anderen Ann. Phys. Chem. 143 337-54

[36] Darhuber A A and Troian S M 2005 Principles of microfluidic actuation by modulation of surface stresses Annu. Rev. Fluid Mech. 37425

[37] Ivanova N A and Bezuglyi B A 2007 Droplet formation in a thin layer of a two-component solution under the thermal action of laser radiation Colloid J. 69735

[38] Ivanova N A and Bezuglyi B A 2009 Influence of the liquid layer thickness on the growth of droplets controlled by the thermal action of laser radiation Tech. Phys. Lett. 35293

[39] Wegener M, Fevre M, Paschedag A R and Kraume M 2009 Impact of Marangoni instabilities on the fluid dynamic behaviour of organic droplets Int. J. Heat Mass Transfer 522543

[40] Katzenstein J M, Janes D W, Cushen J D, Hira N B, McGuffin D L, Prisco N A and Ellison C J 2012 Patterning by photochemically directing the Marangoni effect $A C S$ Macro Lett. 11150

[41] Yuyama K, Rungsimanon T, Sugiyama T and Masuhara H 2012 Formation, dissolution and transfer dynamics of a millimeter-scale thin liquid droplet in glycine solution by laser trapping J. Phys. Chem. C 1166809

[42] Berendsen C W J, Kuijpers C J, Zeegers J C H and Darhuber A A 2013 Dielectrophoretic deformation of thin liquid films induced by surface charge patterns on dielectric substrates Soft Matter 94900

[43] Korosi G and Kovats E S 1981 Density and surface tension of 83 organic liquids J. Chem. Eng. Data 26323

[44] Kumagai A and Takahashi S 1995 Viscosity and density of liquid mixtures of n-alkanes with squalane Int. J. Thermophys. 16773

[45] Mondello M and Grest G S 1995 Molecular dynamics of linear and branched alkanes J. Chem. Phys. 1037156

[46] Kowert B A and Watson M B 2011 Diffusion of organic solutes in squalane J. Phys. Chem. B 1159687

[47] Weltmann K-D and von Woedtke T 2011 Basic requirements for plasma sources in medicine Eur. Phys. J. Appl. Phys. 551
[48] Tyte D C 1962 Intensity measurements on nitrogen second positive system in a low temperature discharge Proc. Phys. Soc. 801347

[49] Hayakawa R, Yoshimura T, Ashida A, Fujimura N, Kitahata H and Yuasa M 2004 Analysis of nitrogen plasma generated by a pulsed plasma system near atmospheric pressure $J$. Appl. Phys. 966094

[50] Országh J, Danko M, Ribar A and Matejčík Š 2012 Nitrogen second positive system studied by electron induced fluorescence Nucl. Instrum. Meth. Phys. Res. B 27976

[51] Shemansky D E and Broadfoot A L 1971 Excitation of $\mathrm{N}_{2}$ and $\mathrm{N}_{2}^{+}$systems by electrons-I absolute transition probabilities J. Quant. Spectrosc. Radiat. Transfer. 111385

[52] Lommatzsch U, Pasedag D, Baalmann A, Ellinghorst G and Wagner H-E 2007 Atmospheric pressure plasma jet treatment of polyethylene surfaces for adhesion improvement Plasma Process. Polym. 4 S1041

[53] Berendsen C W J, Zeegers J C H and Darhuber A A 2013 Thinning and rupture of liquid films by moving slot jets $J$. Colloid Interface Sci. 407505

[54] Foest R, Kindel E, Lange H, Ohl A, Stieber M and Weltmann K-D 2007 RF capillary jet - a tool for localized surface treatment Contrib. Plasma Phys. 47119

[55] Vig J R 1985 UV/ozone cleaning of surfaces J. Vac. Sci. Technol. A 31027

[56] Dubowski Y, Vieceli J, Tobias D J, Gomez A, Lin A, Nizkorodov S A, McIntire T M and Finlayson-Pitts B J 2004 Interaction of gas-phase ozone at $296 \mathrm{~K}$ with unsaturated self-assembled monolayers: a new look at an old system J. Phys. Chem. A 108 10473-85

[57] Kanazawa S, Kawano H, Watanabe S, Furuki T, Akamine S, Ichiki R, Ohkubo T, Kocik M and Mizeraczyk J 2011 Observation of $\mathrm{OH}$ radicals produced by pulsed discharges on the surface of a liquid Plasma Sources Sci. Technol. 20034010

[58] Belmonte T, Pintassilgo C D, Czerwiec T, Henrion G, Hody V, Thiebaut J M and Loureiro J 2005 Oxygen plasma surface interaction in treatments of polyolefines Surf. Coat. Technol. 20026

[59] Bernardelli E A, Belmonte T, Duday D, Frache G, PoncinEpaillard F, Noël C, Choquet P, Migeon H-N and Maliska A 2011 Interaction mechanisms between $\mathrm{Ar}-\mathrm{O}_{2}$ postdischarge and stearic acid I: behaviour of thin films Plasma Chem. Plasma Process. 31189

[60] Bernardelli E A, Souza T, Mafra M, Maliska A M, Belmonte T and Klein A N 2011 Modification of stearic acid in Ar and Ar- $\mathrm{O}_{2}$ pulsed DC discharge Mater. Res. 14519

[61] Bernardelli E A, Mafra M, Maliska A M, Belmonte T and Klein A N 2013 Influence of neutral and charged species on the plasma degradation of the stearic acid Mater. Res. 16385

[62] Carey B S, Scriven L E and Davis H T 1978 Semiempirical theory of surface tensions of pure normal alkanes and alcohols AIChE J. 241076

[63] Segade L et al 2003 Density, surface tension and refractive index of octane +1 -alkanol mixtures at $T=298.15 \mathrm{~K} \mathrm{~J}$. Chem. Eng. Data 481251

[64] Lechner M D 2008 Surface Tension of Pure Liquids and Binary Liquid Mixtures (Landolt-Börnstein group IV) vol 24 (Berlin Springer)

[65] Berendsen C W J, Zeegers J C, Kruis G C, Riepen M and Darhuber A A 2012 Rupture of thin liquid films induced by impinging air-jets Langmuir 289977

[66] Wedershoven H M J M, Berendsen C W J, Zeegers J C H and Darhuber A A 2014 Infrared laser induced rupture of thin liquid films on stationary substrates Appl. Phys. Lett. 104054101

[67] Wedershoven H M J M, Berendsen C W J, Zeegers J C H and Darhuber A A Infrared laser induced thermocapillary 
deformation and destabilization of thin liquid films on moving substrates to be published

[68] Oron A, Davis S H and Bankoff S G 1997 Long-scale evolution of thin liquid films Rev. Mod. Phys. 69931

[69] Wilson S K 1993 The levelling of paint films IMA J. Appl. Math. 50149

[70] Bangham D H and Saweris Z 1938 The behaviour of liquid drops and adsorbed films at cleavage surfaces of mica Transact. Faraday Soc. 34554

[71] Bahadur P, Yadav P S, Chaurasia K, Leh A and Tadmor R 2009 Chasing drops: following escaper and pursuer drop couple system J. Colloid Interface Sci. 332455

[72] Sellier M, Nock V and Verdier C 2011 Self-propelling, coalescing droplets Int. J. Multiphase Flow 37462

[73] Borcia R and Bestehorn M 2010 Different behaviors of delayed fusion between drops with miscible liquids Phys. Rev. E 82036312
[74] Borcia R and Bestehorn M 2011 On the coalescence of sessile drops with miscible liquids Eur. Phys. J. E 3481

[75] Borcia R and Bestehorn M 2013 Partial coalescence of sessile drops with different miscible liquids Langmuir 294426

[76] Karpitschka S and Riegler H 2012 Noncoalescence of sessile drops from different but miscible liquids: hydrodynamic analysis of the twin drop contour as a self-stabilizing traveling wave Phys. Rev. Lett. 109066103

[77] Karpitschka S and Riegler H 2014 Sharp transition between coalescence and non-coalescence of sessile drops J. Fluid Mech. 743 R1

[78] Karpitschka S, Hanske C, Fery A and Riegler H 2014 Coalescence and noncoalescence of sessile drops: impact of surface forces Langmuir 306826 